\title{
A quantitative structure-activity relationship for the acute toxicity of some epoxy compounds to the guppy
}

\author{
J.W. Deneer, T.L. Sinnige, W. Seinen and J.L.M. Hermens \\ Department of Veterinary Pharmacology, Pharmacy and Toxicology, University of Utrecht, Utrecht, \\ The Netherlands
}

(Received 18 December 1987; accepted 12 April 1988)

The 14 day $\mathrm{LC}_{50}$ values of various epoxy compounds to the guppy (Poecilia reticulata) were determined, and investigated through the construction of a quantitative structure-activity relationship (QSAR). Both hydrophobicity and alkylating potency of the compounds are found to be necessary parameters for the satisfactory description of the $\mathrm{LC}_{50}$ data. The findings of the present study are compared to results published for halogenated alkylating agents (Hermens, 1985), some of which are considerably more toxic than predicted on the basis of the QSAR established for the epoxy compounds.

Key words: Epoxy compound; Acute toxicity; $\mathrm{LC}_{50}$; QSAR; Guppy; Poecilia reticulata

\section{INTRODUCTION}

Epoxides are well-known alkylating agents (Ross, 1962) that find extensive industrial application as precursors in organic synthetic reactions (Hine et al., 1981). Most toxicological research concerning epoxides has centered on the evaluation of mutagenic activity and carcinogenic potential (e.g. Van Duuren et al., 1967a, b; Shimkin et al., 1966; Wade et al., 1978, 1979; Hemminki and Vainio, 1984). The acute toxicity of epoxides, and alkylating agents in general, to aquatic organisms has hardly been investigated. Lipnick et al. (1987) have reported 24-h LC $\mathrm{C}_{50}$ data for 6 epoxy compounds to the goldfish (Carassius auratus). Hermens et al. (1985) have published data concerning the 14-day $\mathrm{LC}_{50}$ of halogenated alkylating agents to the guppy (Poecilia reticulata). The latter authors observed that the rate of reaction with a standard nucleophile (4-nitrobenzylpyridine, NBP) was the predominant parameter for the quantitative description of the $\mathrm{LC}_{50}$ data. Hydrophobicity, ex-

Correspondence to: J.W. Deneer, Department of Veterinary Pharmacology, Pharmacy and Toxicology, University of Utrecht, P.O. Box 80176, 3508 TD Utrecht, The Netherlands. 
pressed as the logarithm of the octanol-water partition coefficient $(\log P$ ) was relatively unimportant. Furthermore, it was observed that toxicity increased with reactivity up to a certain level; a further increase in reactivity did not result in an increase of toxicity. Similar findings were reported by Eder et al. (1982a,b) who studied the relationship between mutagenicity in the Ames test and alkylating potency of halogenated alkylating agents.

The aim of the present study was to establish a quantitative structure-activity relationship (QSAR) for the 14-day $\mathrm{LC}_{50}$ data of epoxy compounds to the guppy, and to compare the present results to the findings reported by Hermens et al. (1985) for halogenated alkylating agents.

\section{MATERIALS AND METHODS}

\section{Acute toxicity to the guppy}

Semi-static 14 day $\mathrm{LC}_{50}$ values were determined as outlined previously (Deneer et al., 1988). At least 5 concentrations, geometrically increasing with a factor of 1.8 , were tested for each compound, exposing 10 fish to each concentration. Actual concentrations of the toxicant were determined at least four times before and four times after renewal of the solutions for 2 concentrations of each compound. Concentrations were determined using gas-liquid chromatography (GLC), which was carried out on a Tracor 550 chromatograph equipped with a flame ionization detector. The columns used consisted of a glass column $(2 \mathrm{~m}, 0.3 \mathrm{~cm}$ i.d.) packed with Porapak Q (Chrompack, 100-120 mesh) and a fused silica capillary column (Chrompack Sil $5-\mathrm{CB}, 10 \mathrm{~m}, 0.22 \mathrm{~mm}$ i.d.). Analyses were carried out by direct aqueous injection of water samples.

$\mathrm{LC}_{50}$ values were calculated from log-logit analysis.

\section{Chemical reactivity}

The reactivity of each compound towards 4-nitrobenzylpyridine (NBP) was determined following the procedure as outlined by Barbin et al. (1975).

In a $25-\mathrm{ml}$ erlenmeyer flask $10 \mathrm{ml}$ ethylene glycol (Merck, p.a.) containing $1 / 3 \mathrm{~g}$ 4-nitrobenzylpyridine (Merck, p.a.) were mixed with $5 \mathrm{ml}$ Tris-buffer ( $\mathrm{pH} \mathrm{7.4)} \mathrm{and}$ $2.25 \mathrm{ml}$ acetone (Merck, p.a.). The resulting mixture was gently shaken in a water bath $\left(37^{\circ} \mathrm{C}\right)$. At the start of the experiment $0.25 \mathrm{ml}$ of a $70 \mathrm{mM}$ solution of the epoxide under investigation in acetone were added to the contents of the erlenmeyer flask, resulting in final concentrations of the epoxide and NBP of $1 \mathrm{mM}$ and $90 \mathrm{mM}$, respectively. At regular intervals, usually each $10 \mathrm{~min}$ for $1.5 \mathrm{~h}$, samples were taken from the reaction mixture. These were diluted $1: 1 \mathrm{v} / \mathrm{v}$ in an acetone-triethylamine $(1: 1 \mathrm{v} / \mathrm{v})$ mixture, and left standing in cold $\left(0^{\circ} \mathrm{C}\right)$ water. The absorbance of the reaction product was determined exactly $2 \mathrm{~min}$ after the addition of triethylamine to the sample.

Absorbances were measured using a Pye Unicam 8600 UV/VIS spec- 
trophotometer, which was operated at 560 nanometer. If extinction values became $>1$, samples were diluted with larger volumes of the acetone-triethylamine mixture immediately after they were taken from the reaction mixture.

Pseudo first-order reaction rate constants $\left(k_{1}\right)$ were calculated by linear regression of extinction vs. time, as outlined by Hermens et al. (1985). For all reaction products a molar extinction coefficient equal to $3.7 \times 10^{4} 1(\mathrm{~mol} \mathrm{~cm})^{-1}$ was assumed in the calculations. Hermens et al. (1985) have shown that this value is typical for a broad range of substrates in the NBP test. All determinations of $k_{1}$ were carried out twice; the duplicates were never measured on the same day, and for each determination a freshly prepared stock solution of the test compound was prepared.

The possibility of systematic errors due to hydrolysis of the epoxide during the NBP-test was investigated for three compounds (epichlorohydrin, epibromohydrin and 1,3-butadienediepoxide) by exposing these epoxy-compounds to a mixture similar to the reaction mixture outlined above, but which contained no NBP. After $2 \mathrm{~h}$ NBP was added, and reaction rate constants were determined as usual. A significant lowering of the epoxide concentration during the first $2 \mathrm{~h}$ was not noticed for any of the compounds. Ross (1950) has reported halflives of various of the presently tested epoxy compounds in neutral aqueous solutions well in excess of $24 \mathrm{~h}$. This makes it unlikely that during the time the alkylation tests lasted, typically $90 \mathrm{~min}$, a significant amount of the epoxy compound was hydrolyzed.

\section{Partition coefficients}

For most of the compounds tested no octanol-water partition coefficients were readily available in the literature. Furthermore, the calculation methods as outlined by Hansch and Leo (1979) and Rekker (1977) could not be used since no $\pi$ and $f$ constants for the oxirane-moiety are known. It was therefore decided to establish a Rekker $f$ value for the oxirane fragment

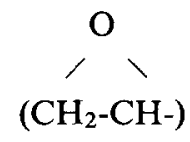

by measuring partition coefficients for several of the compounds studied. This $f$ value was then used to calculate $\log P$ for all compounds.

Octanol-partition coefficients were determined using the 'slow-stirring' method as outlined by Brooke et al. (1986). The classical shake flask method was found to be less useful, since various of the compounds tested lead to the formation of rather stable emulsions.

Approximately $500 \mathrm{ml}$ of distilled water and a small Teflon stirring bar were placed in a glass flask. After placing the flasks lid, approx. $5 \mathrm{ml}$ of $n$-octanol (Merck, p.a.) were placed on top of the water layer. $50-100 \mu \mathrm{l}$ of the test compound were pipetted into the octanol layer, after which the contents of the flask were stirred very 
slowly, being careful not to cause any mixing of the two phases. All determinations were carried out at room temperature. Some preliminary experiments indicated that a 1-day period sufficed to reach equilibrium between the two phases. Small samples of the water and octanol phases were then pipetted out of the flask and analyzed for their epoxide-content by GLC.

All determinations were carried out 3 times. For each compound tested an $f$ fragment value for the oxirane-group (denoted $f^{*}$ ) was calculated as the difference between the actual $\log P$ and the calculated (Rekker, 1977) $\Sigma f$ of the molecule without the oxirane-fragment. For the calculation of $\Sigma f$ of epichlorohydrin, epibromohydrin and glycidol a term was included to reflect the proximity effect (Rekker, 1977). Since the electronegative group (chlorine, bromine and hydroxyl resp.) and the oxygen-atom of the oxirane moiety are separated by 2 carbon atoms, the pe2 term was used, which accounts for a 2-atom separation of electronegative centers.

\section{RESULTS}

\section{Acute toxicity}

$\mathrm{LC}_{50}$ values for all compounds tested are given in Table I. Measured oxygen content was never below $4.6 \mathrm{mg} / 1$, and typically above $6.0 \mathrm{mg} / \mathrm{l}$, after $24 \mathrm{~h}$. The $\mathrm{pH}$ of the solutions was always between 6.8 and 7.1 .

\section{TABLE I}

Toxicity data and pseudo first-order reaction rate constants of the reaction with NBP for all compounds tested.

\begin{tabular}{lcr}
\hline Compound & $\log \mathrm{LC}_{50}{ }^{\mathrm{a}}$ & $\log k_{1}^{\mathrm{b}}$ \\
\hline 1. Propylene oxide & 2.74 & -0.11 \\
2. Glycidol & 2.83 & -0.13 \\
3. Epichlorohydrin & 0.85 & 0.31 \\
4. Epibromohydrin & 0.77 & 0.28 \\
5. 1,2-Epoxybutane & 2.66 & -0.19 \\
6. 1,2-Epoxyhexane & 2.27 & -0.26 \\
7. 1,2-Epoxyoctane & 1.91 & -0.25 \\
8. 1,2-Epoxydecane & 1.32 & -0.19 \\
9. 1,2-Epoxydodecane & 0.78 & -0.16 \\
10. 1,2-Epoxyhexadecane & - & -0.46 \\
11. Styrene oxide & 1.77 & -0.03 \\
12. 1,3-Butadienediepoxide & 1.49 & 0.48 \\
13. 1,2,7,8-Diepoxyoctane & 1.67 & 0.01 \\
14. 4-Nitrobenzylbromide & $-0.30^{\mathrm{c}}$ & 0.16 \\
15. Benzylchloride & $0.49^{\mathrm{c}}$ & 0.16 \\
16. Allylchloride & $1.20^{\mathrm{c}}$ & -0.39 \\
\hline
\end{tabular}

a 14-Day semi-static $\mathrm{LC}_{50}$ to the guppy in $\mu \mathrm{mol} / \mathrm{l}$.

b Pseudo first-order reaction rate constant $\left(\right.$ day $\left.^{-1}\right)$.

c Data taken from Hermens et al. (1985). 
The concentrations of the test compound immediately before renewal of the solutions always corresponded to $>50 \%$ of the material originally added. The $\mathrm{LC}_{50}$ values reported are based on the added amounts of material, and are not corrected for any loss of the compound.

For 1,2-epoxyhexadecane no $\mathrm{LC}_{50}$ could be determined. It seems likely that the solubility of this compound is too low to cause the lethal effect.

Most deaths occurred within the first 10 days of the experiments. At concentrations close to $\mathrm{LC}_{50}$ there were often no deaths during the first 5 days.

It was observed that some fish showed very peculiar behaviour. One fish, which had been exposed to styrene oxide at a concentration corresponding to approximately $0.5 \mathrm{LC}_{50}$ and survived, was placed in clean water after the end of the experiment and carefully observed for several days. The water was renewed daily. The fish usually swam quite sluggishly, showing some loss of balance. On tapping the glass vessel gently it became very excited, swimming in circles very fast. After several seconds it suddenly stopped swimming. Some minutes later all movements of fins etc. stopped, and the fish appeared to be dead. No gill movement was discernible at this point. After periods ranging from 10 to $30 \mathrm{~min}$ the fish recovered and swam around sluggishly again. This procedure was repeated several times during a 5-day period, and the fish always showed the same behaviour. After approximately 7 days in the clean water the fish had recovered completely, swimming normally and not showing the behaviour outlined above.

Fish exposed for some time (typically 5 to 7 days) to lethal concentrations of epichlorohydrine and epibromohydrine started to swim almost continuously in circles very fast. All fish that showed this behaviour died within $24 \mathrm{~h}$ after the first occurrences of these symptoms.

\section{Chemical reactivity}

The reactivity of all compounds tested is given in Table I. In order to be able to compare the present results with data given by Hermens et al. (1985) the reactivity of some halogenated alkylating agents was determined as well. All reaction rate con-

\section{TABLE II}

Experimental octanol-water partition coefficients for several epoxy compounds.

\begin{tabular}{lrc}
\hline Compound & \multicolumn{1}{c}{$\log P^{\mathrm{a}}$} & \multicolumn{1}{c}{$f^{* \mathrm{~b}}$} \\
\hline 1. Propylene oxide & $0.08 \pm 0.05$ & -0.62 \\
2. Glycidol & $-0.95 \pm 0.27$ & -0.50 \\
3. Epichlorohydrin & $0.45 \pm 0.08$ & -0.60 \\
4. Epibromohydrin & $0.85 \pm 0.12$ & -0.37 \\
5. 1,2-Epoxyhexane & $1.93 \pm 0.02$ & -0.36 \\
6. 1,3-Butadienediepoxide & $-0.28 \pm 0.19$ & -0.37 \\
\hline
\end{tabular}

\footnotetext{
a Experimental octanol-water partition coefficient; value given as mean \pm SD of 3 determinations.

b Fragmental $f$ constant (Rekker, 1977) for the oxirane-moiety calculated from $\log P$.
} 


\section{TABLE III}

Comparison of experimental and predicted acute toxicity for all compounds tested.

\begin{tabular}{|c|c|c|c|c|c|c|}
\hline \multirow[t]{2}{*}{ Compound } & \multirow[t]{2}{*}{$\log P^{a}$} & \multirow[t]{2}{*}{$\log k_{1}^{\mathrm{b}}$} & \multicolumn{3}{|c|}{$\log \mathrm{LC}_{50}$} & \multirow{2}{*}{$\begin{array}{l}\mathrm{LC}_{50 \mathrm{MT}} \\
\mathrm{LC}_{50_{\mathrm{exp}}}\end{array}$} \\
\hline & & & $\exp ^{c}$ & $\mathrm{calc}^{\mathrm{d}}$ & residual & \\
\hline 1. Propylene oxide & 0.23 & -0.11 & 2.74 & 2.49 & 0.25 & 85 \\
\hline 2. Glycidol & -0.92 & -0.13 & 2.83 & 3.00 & -0.17 & 692 \\
\hline 3. Epichlorohydrin & 0.58 & 0.31 & 0.85 & 1.08 & -0.23 & 3276 \\
\hline 4. Epibromohydrin & 0.38 & 0.28 & 0.77 & 1.25 & -0.48 & 5880 \\
\hline 5. 1,2-Epoxybutane & 0.76 & -0.19 & 2.66 & 2.52 & 0.14 & 35 \\
\hline 6. 1,2-Epoxyhexane & 1.82 & -0.26 & 2.27 & 2.32 & -0.05 & 10 \\
\hline 7. 1,2-Epoxyoctane & 2.88 & -0.25 & 1.91 & 1.87 & 0.04 & 3 \\
\hline 8. 1,2-Epoxydecane & 3.94 & -0.19 & 1.32 & 1.27 & 0.05 & 1 \\
\hline 9. 1,2-Epoxydodecane & 5.00 & -0.16 & 0.78 & 0.76 & 0.02 & 1 \\
\hline 10. 1,2-Epoxyhexadecane & 7.12 & -0.46 & - & & & - \\
\hline 11. Styrene oxide & 1.43 & -0.03 & 1.77 & 1.77 & 0.00 & 72 \\
\hline $\begin{array}{l}\text { 12. 1,3-Butadiene- } \\
\text { diepoxide }\end{array}$ & -0.48 & 0.48 & 1.49 & 0.98 & 0.51 & 6275 \\
\hline 13. 1,2,7,8-Diepoxy- & & & & & & \\
\hline octane & 1.18 & 0.01 & 1.67 & 1.75 & -0.08 & 149 \\
\hline 14. 4-Nitrobenzyl & & & & & & \\
\hline bromide & 2.41 & 0.16 & $-0.30^{\mathrm{f}}$ & 0.83 & -1.13 & 1184 \\
\hline 15. Benzylchloride & 2.48 & 0.16 & $0.49^{f}$ & 0.80 & -0.31 & 167 \\
\hline 16. Allylchloride & 1.53 & -0.39 & $1.20^{\mathrm{f}}$ & 2.82 & -1.62 & 218 \\
\hline
\end{tabular}

${ }^{\text {a }}$ Octanol-water partition coefficient calculated after Rekker (1977), employing the $f^{*}$ value established in the present study for the oxirane fragment where necessary.

${ }^{b}$ Pseudo first-order reaction rate constant towards 4-nitrobenzylpyridine $\left(\right.$ day $\left.^{-1}\right)$.

' Experimental 14 day semi-static $\mathrm{LC}_{50}$ to the guppy in $\mu \mathrm{mol} / 1$.

${ }^{d} 14$ day $\mathrm{LC}_{50}$ calculated using eq. (3).

${ }^{\mathrm{e}} \mathrm{LC} \mathrm{C}_{50 \mathrm{MT}}$ denotes $\mathrm{LC}_{50}$ expected on the basis of an anaesthetic mode of action: $-\log \mathrm{LC}_{50 \mathrm{MT}}=0.87 \mathrm{log}$ $P-4.87$ (Könemann, 1981).

' Data taken from Hermens et al. (1985).

stants are given as pseudo first-order rate constants. Epichlorohydrin, epibromohydrin and 1,3-butadienediepoxide are substantially more reactive than the other compounds tested. This is in good agreement with data given by Ross (1950) and Hemminki et al. (1980).

\section{Hydrophobicity}

Experimental values of the logarithm of the octanol-water partition coefficient $(\log P)$ as well as calculated values for $f^{*}$ are given in Table II for several compounds. The mean value of $f^{*}$ calculated for all six compounds was $-0.47 \pm 0.12$. Calculated values of $\log P$ for all compounds are given in Table III. 


\section{QSAR-analysis}

Several QSARs were calculated for the epoxy compounds. Equations (1) and (2) were calculated using $\log P$ and $\log k_{1}$ as the only parameter respectively. These QSARs are of relatively poor quality, which is evident from the relatively small correlation coefficient $(r)$ and the large standard error of estimate $(s)$ :

$-\log \mathrm{LC}_{50}=(0.18 \pm 0.12) \log P-2.00, N=12, r=0.419, s=0.72$,

$-\log \mathrm{LC}_{50}=(1.58 \pm 0.84) \log k_{1}-1.72, N=12, r=0.513, s=0.68$.

A much better QSAR is obtained when combining these two parameters, as shown in eq. (3):

$-\log \mathrm{LC}_{50}=(0.39 \pm 0.05) \log P+(3.0 \pm 0.4) \log k_{1}-2.25, N=12$, $r=0.945, s=0.27$.

The partial $F$ values for the $\log P$ and $\log k_{1}$ coefficients in eq. (3) are 53.3 and 60.6 , respectively, showing that both terms are highly significant $(P<0.01)$. The standard error of estimate of eq. (3) is only slightly larger than the expected experimental error in the $\mathrm{LC}_{50}$ values. The correlation between $\log P$ and $\log k_{1}$ is only moderate $(r=0.512)$, indicating that these two parameters are to a large extent independent of each other.

\section{DISCUSSION}

It is obvious from Fig. 1 that, for the epoxy compounds tested, the relationship between acute toxicity and alkylating potency is different from the hyperbolic relationship observed by Hermens et al. (1985) for halogenated alkylating agents. Furthermore, inspection of Table III reveals that 2 of the 3 halogenated alkylating agents tested are substantially more toxic than predicted from the QSAR established

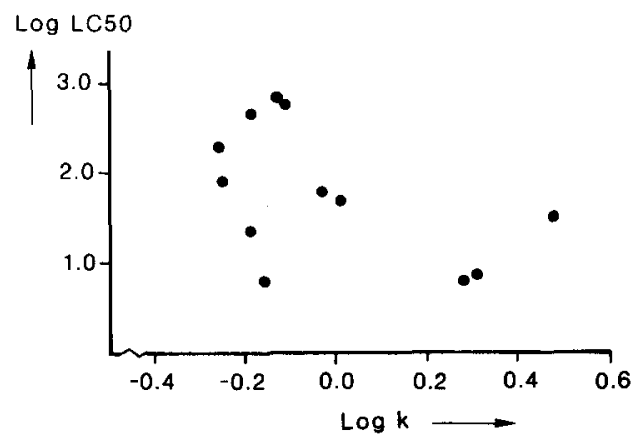

Fig. 1. The 14-day $\operatorname{LC}_{50}(\mu \mathrm{mol} / \mathrm{l})$ of epoxy compounds as a function of their alkylating potency. 
for the epoxy compounds. Both classes of chemicals are expected to exert their toxic effect through very similar mechanisms, i.e. alkylation of macromolecules. Assuming similar mechanisms, differences in toxicity between equally hydrophobic and reactive halogenated alkylating agents and epoxy compounds may possibly be attributed to differences in the rates of in vivo transformation reactions which these compounds undergo. Halogenated agents are expected to be predominantly transformed through conjugation with glutathione, whereas epoxides may also be transformed through hydrolysis reactions (Bock et al., 1987; Nimmo, 1987). More detailed information about the various transformation reactions and their in vivo rates would be necessary, however, to quantitatively account for the observed differences between the acute toxicity of halogenated compounds and epoxides.

Both hydrophobicity and alkylating potency are necessary parameters for a sufficiently accurate description of the acute toxicity data. This is plausible in view of the fact that the descriptors used in a QSAR equation reflect the rate limiting processes involved in the development of the toxic effect (Hansch and Fujita, 1964). The description of the acute toxicity of halogenated compounds given by Hermens et al. (1985), employing alkylating potency as the only parameter, suggests that reaction of the alkylating agents with in vivo nucleophilic centers constitutes the sole rate limiting process. The present findings suggest that for epoxy compounds the development of the toxic effect may be divided into at least two processes, whose rate is governed by hydrophobicity and chemical reactivity respectively. Furthermore, it is expected that the in vivo rates of these two processes are similar. If there were large differences in the rates at which the processes occurred, the parameter reflecting the faster of the two processes would not be needed for a satisfactory description of the biological data. It is, however, not clear which factors are responsible for the observed differences in the description of the $\mathrm{LC}_{50}$ data of epoxides and halogenated alkylating agents.

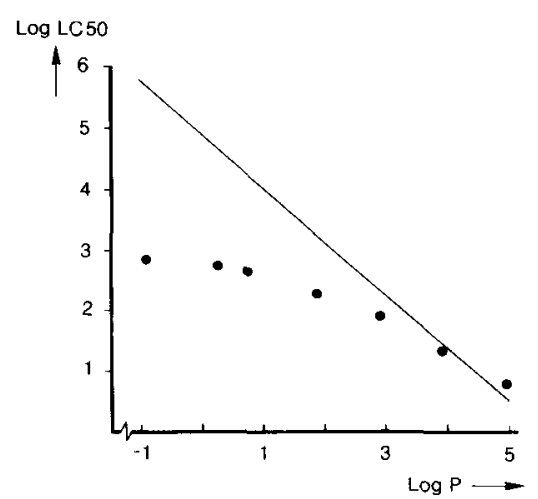

Fig. 2. The 14-day $\operatorname{LC}_{50}(\mu \mathrm{mol} / \mathrm{l})$ of some epoxy compounds of similar reactivity $\left(-0.26<\log k_{1}<\right.$

-0.09 ) as a function of their hydrophobicity; line drawn denotes 'minimum toxicity' expected for chemicals acting through narcosis $\log \mathrm{LC}_{50 \mathrm{MT}}=4.87-0.87 \log P$ (Könemann, 1981). 
Könemann (1981) and Veith et al. (1983) have established QSARs for the acute toxicity $\left(\mathrm{LC}_{S 0}\right)$ to the guppy and fathead minnow respectively, of relatively unreactive organic compounds that are assumed to act solely through depression of the central nervous system in a way similar to general anaesthetics. These QSARs are expected to predict minimal toxicity, i.e. each organic compound is at least as toxic as predicted on the basis of these QSARs. Epoxy compounds are, because of their reactive nature, expected to be more toxic than predicted by these QSARs. Table III shows the ratio between experimental $\mathrm{LC}_{50}$ values and the $\mathrm{LC}_{50 \mathrm{MT}}$ expected for general anaesthetics, as predicted from the Könemann equation - log $\mathrm{LC}_{50 \mathrm{MT}}=0.87 \log P-4.87$ (Könemann, 1981). The most reactive compounds, epibromohydrin, epichlorohydrin and 1,3-butadienediepoxide, are substantially more toxic than general anaesthetics of similar hydrophobicity. Considering only compounds with similar reactivity (e.g. $-0.27<\log k_{1}<-0.09$ ) it is obvious that an increase of lipophilicity is accompanied by a decrease of the ratio between $\mathbf{L C}_{50 \mathrm{MT}}$ and $\mathrm{LC}_{50 \mathrm{exp}}$ (Fig. 2). This phenomenon has previously been observed for the acute toxicity of esters (Veith et al., 1984-85), aldehydes (Deneer et al., 1987) and epoxy compounds (Lipnick et al., 1987). A possible explanation may be that the more hydrophobic chemicals are less available for chemical reactions taking place in the aqueous phases within the organism, since an increasing fraction of the compound is deposited in lipid phases. If the toxic effect is caused by reactions proceeding in the aqueous phases, the more hydrophobic chemicals will be relatively nontoxic, since they are only to a slight extent present in the aqueous phases. This will ultimately result in the most hydrophobic chemicals acting predominantly as general anaesthetics.

\section{ACKNOWLEDGEMENTS}

These investigations were supported by The Netherlands Foundation for Technical Research (STW), future Technical Science Branch/Division of The Netherlands Organization for the Advancement of Pure Research (ZWO), and by the Dutch Ministry of Transport and Public Works.

\section{REFERENCES}

Barbin, A., H. Brésil, A. Croisy, P. Jacquignon, C. Malaveille, R. Montesano and H. Bartsch, 1975. Liver-microsome-mediated formation of alkylating agents from vinyl bromide and vinyl chloride. Biochem. Biophys. Res. Commun. 67, 596-603.

Bock, K.W., W. Lilienblum, G. Fischer, G. Schirmer and B.S. Bock-Hennig, 1987. The role of conjugation reactions in detoxication. Arch. Toxicol. 60, 22-29.

Brooke, D.N., A.J. Dobbs and N. Williams, 1986. Octanol:water partition coefficients $(P)$ : measurement, estimation and interpretation; particularly for chemicals with $P>10^{5}$. Ecotoxicol. Environ. Saf. 11, 251-260.

Deneer, J.W., W. Seinen and J.L.M. Hermens, 1988. The acute toxicity of aldehydes to the guppy. Aquat. Toxicol. 12, 185-192. 
Eder, E., D. Henschler and T. Neudecker, 1982a. Mutagenic properties of allylic and $\alpha, \beta$-unsaturated compounds: consideration of alkylating mechanisms. Xenobiotica 12, 831-848.

Eder, E., T. Neudecker, D. Lutz and D. Henschler, 1982b. Correlation of alkylating and mutagenic activities of allyl and allylic compounds: standard alkylation test vs. kinetic investigation. Chem. Biol. Interact. 38, 303-315.

Hansch, C. and A. Leo, 1979. Substituent constants for correlation analysis in chemistry and biology. John Wiley and Sons, New York.

Hansch, C. and T. Fujita, 1964. Q- $\sigma-\pi$ Analysis. A method for the correlation of biological activity and chemical structure. J. Am. Chem. Soc. 86, 1616-1626.

Hemminki, K. and H. Vainio, 1984. Genotoxicity of epoxides and epoxy compounds. Industrial hazard of plastics and synthetic elastomers, Alan R. Liss Inc., New York, pp. 373-384.

Hemminki, K., K. Falck and H. Vainio, 1980. Comparison of alkylation rates and mutagenicity of directly acting industrial and laboratory chemicals. Arch. Toxicol. 46, 277-285.

Hermens, J., F. Busser, P. Leeuwangh and A. Musch, 1985. Quantitative correlation studies between the acute lethal toxicity of 15 organic halides to the guppy (Poecilia reticulata) and chemical reactivity towards 4-nitrobenzylpyridine. Toxicol. Environ. Chem. 9, 219-236.

Hine, C., V.K. Rowe, E.R. White, K.I. Darmer and G.T. Youndblood, 1981. Epoxy compounds. In: Patty's industrial hygiene, Vol. 2A, Ch. 32, edited by G.D. Clayton and F.E. Clayton, John Wiley and Sons, New York.

Könemann, H., 1981. Quantitative structure-activity relationships in fish toxicity studies. I. Relationship for 50 industrial pollutants. Toxicology 19, 209-221.

Lipnick, R.L., K.R. Watson and A.K. Strausz, 1987. A QSAR study of the acute toxicity of some industrial organic chemicals to goldfish. Narcosis, electrophile and proelectrophile mechanisms. Xenobiotica 17, 1011-1025.

Nimmo, 1.A., 1987. The glutathione S-transferases of fish. Fish Physiol. Biochem. 3, 163-172.

Rekker, R.F., 1977. The hydrophobic fragmental constant. Elsevier, Amsterdam/New York.

Ross, W.C.J., 1950. The reactions of certain epoxides in aqueous solutions. J. Chem. Soc. 2257-2272.

Ross, W.C.J., 1962. Biological alkylating agents. Butterworths, London.

Shimkin, M.B., J.H. Weisburger, E.K. Weisburger, N. Gubareff and V. Suntzeff, 1966. Bioassay of 29 alkylating chemicals by the pulmonary-tumor response in strain A mice. J. Nat. Cancer Inst. 36, 915-935.

Van Duuren, B.L., L. Langseth, L. Orris, M. Baden and M. Kuschner, 1967a. Carcinogenicity of epoxides, lactones, and peroxy compounds. V. Subcutaneous injection in rats. J. Nat. Cancer Inst. 39, $1213-126$.

Van Duuren, B.L., L. Langseth, B.M. Goldschmidt and L. Orris, 1967b. Carcinogenicity of epoxides, lactones, and peroxy compounds. VI. Structure and carcinogenic activity. J. Nat. Cancer Inst. 39, $1217-1228$.

Veith, G.D., D.J. Call and L.T. Brooke, 1983. Structure-toxicity relationships for the fathead minnow, Pimephales promelas: Narcotic industrial chemicals. Can. J. Fish. Aquat. Sci. 40, 743-748.

Veith, G.D., D. DeFoe and M. Knuth, 1984-85. Structure-activity relationships for screening organic chemicals for potential ecotoxicity effects. Drug Metab. Rev. 15, 1295-1303.

Wade, D.R., S.C. Airy and J.E. Sinsheimer, 1978. Mutagenicity of aliphatic epoxides. Mutat. Res. 58, 217-223.

Wade, M.J., J.W. Moyer and C.H. Hine, 1979. Mutagenic action of a series of epoxides. Mutat. Res. $66,367-371$. 